\title{
European Patent Office grants controversial patent protecting virus: lessons from the Middle East respiratory syndrome coronavirus outbreak
}

\author{
The scope of patents covering SARS-CoV-2 and diagnostics, vaccines and treatments related to the virus remains \\ unclear, but the pandemic may have created a permanent demand for SARS-CoV-2-related products and spark \\ long-term interest in relevant intellectual property rights.
}

\begin{abstract}
n June 2012, a novel coronavirus first identified in a patient in Jeddah, Saudi Arabia, led to the outbreak of Middle East respiratory syndrome (MERS). The MERS coronavirus (MERS-CoV), like the virus causing severe acute respiratory syndrome (SARS), was considered a major public health threat, with almost 900 deaths in 27 countries to date ${ }^{1}$. A debate about the commercial rights associated with the virus was triggered after Erasmus University Medical Center (Erasmus MC), one of the largest university medical centers in Europe, filed a patent application and provided samples of the virus to other labs only through a material transfer agreement $(\mathrm{MTA})^{2}$, an agreement that governs what the recipient of a sample may do with it.

High-ranking politicians and researchers were quick to criticize Erasmus MC, accusing it of monopolizing the virus and stifling research ${ }^{3}$. Erasmus MC assured the public that they would not own the virus and that their patent would be limited to practical applications, such as diagnostic tests, vaccines and antiviral treatments ${ }^{4}$. Now, seven years later, the European Patent Office (EPO) has granted European patent EP 2898067 to Erasmus MC 5 . In contrast to Erasmus's public statement, however, it appears that claims 1 to 4 of the patent do protect the virus as such.
\end{abstract}

By November 2019, 2,494 confirmed cases of MERS-CoV had been reported to the World Health Organization ${ }^{1}$. Fortunately, despite initial concerns, it has remained a rare disease worldwide. By contrast, the recent outbreak of severe acute respiratory syndrome coronavirus 2 (SARS-CoV-2) ${ }^{6}$, a much more transmissible virus than MERS, has resulted in a global pandemic with 100 million cases and over two millions deaths thus far. The public discussion is focused on the day-to-day management of the disease rather than on complex legal issues. Nevertheless, the considerable market value of diagnostically and therapeutically useful products means that questions about commercial rights are inevitable.

At present, most major research institutions are involved in combatting SARS-CoV-2. On the one hand, their researchers may feel obliged to make their results available to the public without undue restrictions and without delay, for the sake of public health. On the other hand, they have a legitimate interest in being rewarded for their outstanding achievements, particularly after investing considerable resources and working under enormous pressure in an extremely competitive field. Here we discuss the issues and challenges associated with securing commercial rights related to inventions in the field of coronavirus research, drawing on experiences from the MERS outbreak and considering ways to ensure that intellectual property rights drive innovation rather than impede it.

\section{Crucial access to index patient samples} Every notable virus infection starts with a first documented case, known as the index case. Samples from this case are invaluable for research because they are the first available source of the pathogen and can be used to sequence genomes and generate reagents and research tools, including cell lines, animal models, vaccines and human antibodies. Consequently, those in possession of such samples have a considerable advantage, particularly if they also control access to them.

In 2012, Erasmus MC was the first to obtain access to the MERS virus. They sequenced its genome and readily distributed samples to other laboratories, subject to those laboratories signing an MTA. Some criticized this MTA for slowing the potential progress of other labs by at least several weeks and for being too restrictive. Erasmus MC representatives argued that MTAs are common practice when shipping viruses and that the company gave the virus to any lab that asked for $i t^{3}$.
In 2013, the Erasmus MC MTA was made public in accordance with US law regarding public records ${ }^{7}$. The agreement includes typical clauses relating to the ethical and safe use of and access to the virus (for example, limiting transfer of the virus to third parties and obligating the recipient to seek approvals before conducting studies on living human subjects). Such wording is essential to establish precautions for distributing hazardous biological material such as lethal viruses. It would have been irresponsible for the MTA to omit such precautions.

The Erasmus MC MTA does not impose unreasonable limitations on academic research. However, it stipulates that any inventions directly related to the material provided, explicitly including derivatives, clones and subunits of the virus, as well as products expressed by the virus, are owned by Erasmus MC, even when conceived by the recipient. This broad definition of material includes technologies developed using the sample and materials made from components of the virus, such as vaccines and diagnostic assays comprising specific antigens. This wording implies that many MERS-related patents would be assigned to Erasmus MC. Such clauses can be appropriate if the transferred material is an invention conceived by the provider, as they can prevent recipients' inventions from undermining the provider's intellectual property. However, such wording raises concerns about profiting from technology that depends only on obtaining a naturally occurring virus. A better approach may involve drafting separate clauses: those regarding intellectual property related to the unaltered virus, which should be made available without special conditions or restrictions, and those regarding any information or reagents developed by the provider for commercial use, which may be subject to restrictions. In this way, the virus itself is not monopolized, and those 
receiving it cannot take credit for the provider's achievements.

As for the delay associated with the MTA drafting, public organizations such as the World Health Organization and the World Intellectual Property Organization could provide templates of agreements tailored for such transfers. It should be possible to sign drafts from a neutral source without lengthy negotiations and amendments, possibly within one or two days. Labs interested in receiving samples could use such templates to improve their negotiation position if faced with unreasonably restrictive drafts. Finally, academic institutions may consider authorizing principal investigators to sign such documents to save more time.

\section{Whoever has shall be given more}

An MTA limits use of the material transferred, but the recipient remains free to use material obtained from other sources without any limitations. In this way, an MTA grants fewer rights than a patent, which confers the right to exclude anyone from using the protected invention for up to 20 years, regardless of the origin of any material used. The scientists with first access to samples from the index case are likely to be the first to obtain patentable results and to file applications, which can further limit the progress of other academic and commercial competitors, in addition to the limitations associated with the MTA. Given that Erasmus MC was the first institution with sequencing facilities to work with the MERS virus, it is not surprising that it was the first to file a patent application. However, the scope of the patent granted by the EPO - particularly the fact that the virus itself was protected - is unexpected.

The EPO uses the European Directive on the Protection of Biotechnological Inventions (98/44/EC) to interpret the European Patent Convention. This directive states that biological material, even naturally occurring viruses, may be patentable. However, it must first be determined whether the subject matter of any claim is novel and based on an inventive step. Shortly after the MERS outbreak was reported in June 2012 and before the patent application was filed, one of the inventors published a blog message disclosing the existence of the virus, the culturing conditions and a preliminary characterization ${ }^{8}$. The timing of this blog post challenges the novelty of any claim regarding the virus. Moreover, another infected patient was reported in London before the patent application was filed ${ }^{9}$. A virus culture could have been isolated from this patient using prepublished methods and reagents, including standard commercial kits ${ }^{10,11}$.
The EPO deemed the blog post to be non-enabling because, in order for a material to qualify as having been publicly available, case law requires a notice that samples can be obtained. The blog post indicated that the inventors would collaborate with others, which usually involves sharing essential samples, thus fulfilling the notice requirement. In addition, the availability of the virus through the other case should be considered. Overall, some uncertainty remains whether the EPO was right to grant such a broad patent.

\section{The impact of the patent on research}

It was alleged in early 2013 that patenting the MERS virus hampered the rapid development of diagnostics, specifically in Saudi Arabia, and that the novelty requirement for patentability may have tempted scientists to delay the publication of data urgently needed to contain the virus and to develop diagnostics ${ }^{12}$. However, a recent comprehensive survey showed that relevant patents do not affect most diagnostic labs in terms of their innovation, product development and provision of diagnostic services, although a nominal increase in the number of affected labs was observed ${ }^{13}$. Moreover, a patent can be enforced only once it is published and granted, which usually takes at least 18 months. Thus, the patent application for MERS, which was unpublished in 2013, conferred no protection. In fact, no application was ever filed in Saudi Arabia. Recall that the blog post containing preliminary data on the new human coronavirus $^{8}$ was published before the first priority patent application filing, further suggesting that its author's priority was to inform the public early rather than optimize patent protection. In addition, antigen sequences published by the inventors only three months after the first isolation of the virus may have significantly aided researchers in developing diagnostics or vaccines. With all this in mind, it seems inappropriate and unjustified to blame these scientists for hindering research.

It is possible that fear of competition or the race to be first may lead to the withholding of information, but this problem is not unique to intellectual property rights. For example, authors of academic publications may withhold information to preserve the surprise associated with unexpected results and maximize the impact of a newly published paper. Commercially minded academic inventors also may be tempted to wait until their business partners make progress on a potential product before publicizing information that aids in that development.
Scientific journals address this problem by allowing authors to publish their manuscripts on preprint servers. Such non-peer-reviewed papers do not compromise the originality of the results. As for patents, the introduction of a worldwide grace period, as already established in the United States, may help overcome this problem. Any publication by the inventors during this grace period, which occurs before the filing of the patent application, would be disregarded in the assessment of patentability. Interestingly, a grace period limited to inventions disclosed for the sake of public interest in time of a national emergency or exceptional circumstances will be introduced into the Chinese patent law, obviously based on experience from the SARS-CoV-2 outbreak. A drawback of this approach is that it may be difficult to determine whether a publication is based on the inventors' work, especially when information is published in social media posts, which often lack full citations. This lack of transparency can decrease the legal certainty regarding the validity of patents protecting prepublished inventions.

\section{"Given that Erasmus MC was the first institution with sequencing facilities to work with the MERS virus, it is not surprising that it was the first to file a patent application. However, the scope of the patent granted by the European Patent Office - particularly the fact that the virus itself was protected - is unexpected."}

Erasmus MC argued that a patent was necessary to attract investments in the development of diagnostics, vaccines and drugs ${ }^{13}$. However, the contributions by academic researchers should not be neglected. For instance, academics published numerous protocols for diagnostic assays soon after the recent SARS-CoV-2 outbreak, and no patent applications were disclosed in their publications, indicating they did not seek intellectual property protection ${ }^{14,15}$. Other academic groups are running projects with the aim of developing vaccines and drugs against SARS-CoV-2.

Nevertheless, it also is important to distinguish between short-term development aimed at generating publishable results 
and long-term development aimed at developing standardized diagnostic or therapeutic products for routine use. Long-term development faces increasingly strict regulatory requirements, such as those imposed by EU Regulation 2017/746 for registration of in vitro diagnostics. Manufacturers of standardized kits, which are essential for making diagnostic assays widely available at low cost and for conducting large studies across the world under identical conditions, must cope with increasing costs for registration, and may hesitate to invest if there is no patent granting them exclusivity. These costs may become even more restrictive in the research of orphan diseases, such as viral infections with few reported cases (for example, MERS). A patent can thus be a strong incentive for a company to invest long-term in such projects, even if there is no immediate demand for the product. Such investments can be extremely beneficial if they facilitate early access to diagnostic and therapeutic products, for example, by preventing or shortening a global health crisis caused by a virus.

\section{Public relations}

Publicly funded research institutions must balance their roles as independent research organizations and commercial entities. One way to do this is via transparent licensing schemes governed by the research organizations themselves ${ }^{16}$. This transparency should include information relating to the availability of licenses and conditions, as well as the existence and scope of any patents filed. By declaring that the MERS virus would not be patented or owned by them, Erasmus MC representatives implied that anyone in industry or academia could work with the virus, even though they concurrently requested the grant of patent claims protecting it. Researchers who relied on their statement and pursued work with the intact virus may now face some difficult choices: abandon their research projects, hope that the patent will not be enforced against them, or pay unbudgeted royalties. The consequences may be harsh, as many companies in the field of diagnostics (for example, startups) operate on slim budgets, and financial losses may lead to the termination of research projects, staff release or even bankruptcy.

When asked for a comment, Erasmus $\mathrm{MC}$ representatives expressed regret that their language was "legally correct ... only in some parts of the world" and clarified that it was intended to inform the public that the virus would be available for research purposes. To be fair, patent protection for the "virus genome" or subject matter beyond the specific applications of the virus referred to in the press release $e^{4}$ was mentioned in the competing interest section of the paper in which the authors first reported the isolation of the coronavirus in September 2012, well before the publication of the press release ${ }^{10}$. This disclosure suggests that the inventors did not mean to deceive the public, but they may have been unaware of how details such as the difference between the virus itself and applications of it matter in terms of legal consequences. Also, they thoroughly disclosed all financial interests, which many authors omit ${ }^{17}$. Finally, the enormous pressure to publish quickly for the sake of public health cannot be overestimated.

The utmost care should be applied when publicly funded research institutions make public statements regarding their intellectual property. In particular, it should not be suggested that freedom to operate exists where there is none. Those who are actively involved in the commercialization of these assets should avoid any activity that raises suspicions about their scientific independence. As for the MERS patent, Erasmus MC might consider voluntarily limiting their granted patent by deleting any claims relating to the virus itself, which is a straightforward and inexpensive procedure available under the European Patent Convention. This, possibly together with public clarification that licenses will be available with reasonable conditions for companies and for free for academic researchers, may retroactively rectify the discrepancy between the organization's press release and the granted patent.

\section{Conclusions}

In the field of virology, a patent can reward hard-working, highly qualified inventors who often work under uncomfortable conditions for low wages, especially when employed in the public sector. Unfortunately, the work required to complete a patent application can take years to pay off, if it results in any payment at all. If inventors must also be concerned about public accusations regarding their motivations, the disadvantages associated with intellectual property may outweigh potential future benefits, and they may refrain from filing patent applications and eventually seek better-paying employment outside academia. Therefore, any public discussion should be based on well-founded arguments with sufficient attention to important details.

Patents are about more than royalties for the inventors, however. They have considerable consequences for anyone who wants to work with patented technologies for research and development, in both the commercial and academic sectors. Therefore, patents should be used responsibly. Commercialization strategies should ensure that diagnostic services, vaccines and therapies are widely available at affordable prices, and any statements regarding the scope of protection should be accurate.

As a consequence of the MERS patent controversy, a global agreement was suggested in 2013 to clarify the distribution and commercial rights regarding virus samples $^{2}$. Unfortunately, this matter disappeared from public attention, probably owing to the rapid decline in new MERS cases after 2013. The Nagoya Protocol to the Convention on Biological Diversity came into force on 12 October 2014, but lacks harmonized options for the rapid exchange of resources relating to infectious diseases ${ }^{18}$. Regarding intellectual property rights, the protocol is vague, at best. Nevertheless, patent laws constitute a basic legal framework. Thus, a public discussion involving professional scientific and medical societies, legal scholars, international and national health agencies, and governments could help establish concrete guidelines for research institutions and global standards for the disclosure of information, transfer of virus samples and assignment of inventions. Amendments of existing patent laws also should be considered to encourage scientists to disclose their results before filing patent applications. Such amendments will help researchers, especially those in the field of infectious diseases. Whereas researchers in other fields may be able to spend months devising strategies for the commercialization of their inventions, infectious disease researchers must often quickly resolve complex legal and ethical issues when facing a new virus. More research will be required to evaluate whether such guidelines will facilitate the development and early supply of products and services for detecting and treating novel pathogens.

Regarding SARS-CoV-2, it remains unclear whether a patent has been filed that protects the virus and its related products and methods as broadly as the MERS patent. This new coronavirus emerged in late December 2019, and relevant patent publications will likely not be available before June 2021. Nevertheless, the massive extent of the outbreak may create permanent demand for SARS-CoV-2-related products and spark long-term interest in relevant intellectual property rights.

\footnotetext{
Carsten D. Richter ${ }^{\bowtie}$

Institute of Entrepreneurship and Business

Development, University of Lübeck, Lübeck, Germany.

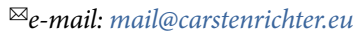


Published online: 10 March 2021

https://doi.org/10.1038/s41587-021-00840-8

\section{References}

1. World Health Organization. Middle East respiratory syndrome coronavirus (MERS-CoV). https://www.who.int/health-topics/ middle-east-respiratory-syndrome-coronavirus-mers (2021).

2. Butler, D. Nature https://doi.org/10.1038/nature.2012.12108 (2013).

3. Kupferschmidt, K. As outbreak continues, confusion reigns over virus patents. Science https://www.sciencemag.org/news/2013/05/ outbreak-continues-confusion-reigns-over-virus-patents (28 May 2013).
4. Erasmus MC press release. Erasmus MC: no restrictions for public health research into MERS coronavirus (24 May 2013).

5. Haagmans, B. L. et al. Human betacoronavirus lineage $V$ and identification of $\mathrm{N}$-terminal dipeptidyl peptidase as its virus receptor. European patent EP2898067B1 (2020).

6. Zhu, N. et al. N. Engl. J. Med. 382, 727-733 (2020).

7. Erasmus MC. Material Transfer Agreement. https://twn.my/ title2/intellectual_property/info.service/2013/ipr.info.130512/ 22227717951a47369b9515.pdf (3 October 2012).

8. Zaki, A.M. PRO/EDR > Novel coronavirus - Saudi Arabia: human isolate. https://promedmail.org/promed-post/? id $=20120920.1302733$ (20 September 2012).

9. Pebody, R. G. et al. Euro Surveill. 17, 20292 (2012).

10. Zaki, A. M., van Boheemen, S., Bestebroer, T. M., Osterhaus, A. D \& Fouchier, R. A. N. Engl. J. Med. 367, 1814-1820 (2012).
11. Bermingham, A. et al. Euro Surveill. 17, 20290 (2012).

12. Mackenzie, D. Saudis say Dutch patent on MERS virus hampers research. New Scientist https://www.newscientist.com/article/ dn23593-saudis-say-dutch-patent-on-mers-virus-hampersresearch/ (24 May 2013).

13. Liddicoat, J. et al. Eur. J. Hum. Genet. 27, 997-1007 (2019). 14. Corman, V.M. et al. Euro Surveill. https://doi.org/10.2807/ 1560-7917.ES.2020.25.3.2000045 (2020).

15. Chu, D. K. W. et al. Clin. Chem. 66, 549-555 (2020).

16. Egelie, K. J., Strand, S. P., Johansen, B. \& Myskja, B. K. Nat. Biotechnol. 36, 495-499 (2018).

17. Lebovitz, R. M. Northwest. J. Tech. \& Intell. Prop. 6, 36-45 (2007).

18. Knauf, S., Abel, L. \& Hallmaier-Wacker, L. K. Bull. World Health Organ. 97, 379 (2019). 